\title{
Wollastonite nanofiber-doped self-setting calcium phosphate bioactive cement for bone tissue regeneration
}

This article was published in the following Dove Press journal:

International Journal of Nanomedicine

10 July 2012

Number of times this article has been viewed

\author{
Han Guo ${ }^{1,2}$ \\ Jie $\mathrm{Wei}^{2}$ \\ Wenhua Song ${ }^{2}$ \\ Shan Zhang ${ }^{2}$ \\ Yonggang Yan $^{3}$ \\ Changsheng Liu ${ }^{2}$ \\ Tiqiao Xiao' \\ 'Shanghai Synchrotron Radiation \\ Facility, Shanghai Institute of Applied \\ Physics, Chinese Academy of Sciences, \\ Shanghai, People's Republic of \\ China; ${ }^{2}$ Key Laboratory for Ultrafine \\ Materials of Ministry of Education, \\ East China University of Science \\ and Technology, Shanghai, People's \\ Republic of China; ${ }^{3}$ School of Physical \\ Science and Technology, Sichuan \\ University, Chengdu, People's Republic \\ of China
}

\begin{abstract}
The purpose of this study was to synthesize a self-setting bioactive cement by incorporation of wollastonite nanofibers (WNFs) into calcium phosphate cement (CPC). The composition, morphology, setting time, compressive strength, hydrophilicity, and degradation of WNF-doped CPC (wnf-CPC) were investigated. Scanning electron microscopy, Fourier transform infrared spectroscopy, X-ray diffraction, and inductively coupled plasma atomic emission spectroscopy were utilized. Additionally, methyl-thiazolyl-tetrazolium bromide assay, scanning electron microscopy, inductively coupled plasma atomic emission spectroscopy, and histological evaluation were used to study the cell and tissue responses to wnf-CPC, both in vitro and in vivo. The results confirmed that the addition of WNFs into CPC had no obvious effect on the setting time or the compressive strength of wnf-CPC, provided the WNF amount was not more than $10 \mathrm{wt} \%$. However, the hydrophilicity and degradability of wnf-CPC were significantly improved by the addition of WNFs - this was because of the change of microstructure caused by the WNFs. The preferred dissolution of WNFs caused the formation of microporosity in wnf-CPC when soaked in tris hydrochloride solution. The microporosity enlarged the surface area of the wnf-CPC and so promoted degradation of the wnf-CPC when in contact with liquid. In addition, MG-63 cell attachment and proliferation on the wnf-CPC were superior to that on the CPC, indicating that incorporation of WNFs into CPC improved the biological properties for wnf-CPC. Following the implantation of wnf-CPC into bone defects of rabbits, histological evaluation showed that wnf-CPC enhanced the efficiency of new bone formation in comparison with CPC, indicating excellent biocompatibility and osteogenesis of wnf-CPC. In conclusion, wnf-CPC exhibited promising prospects in bone regeneration.
\end{abstract}

Keywords: calcium phosphate cement, degradability, cell and tissue responses, biocompatibility

\section{Introduction}

Calcium (Ca) phosphate cements (CPCs) have excellent biocompatibility and osteoconductivity; because of this, CPCs have been widely studied as bone regeneration materials. ${ }^{1}$ A typical CPC composed of the mixed powder of tetracalcium phosphate (TECP) $\left[\mathrm{Ca}_{4}\left(\mathrm{PO}_{4}\right)_{2} \mathrm{O}\right]$ and dicalcium phosphate anhydrous (DCPA) $\left(\mathrm{CaHPO}_{4}\right)$ was first reported by Brown and Chow. ${ }^{2}$ This CPC powder could be mixed with aqueous liquid to form a paste that could set in situ and form apatite as a final product. ${ }^{3} \mathrm{TECP} /$ DCPA-based cements have unique in vivo properties: slow resorption and replacement by new bone. ${ }^{4}$

Previous study has suggested that silicon ( $\mathrm{Si}$ ), as a trace element in animal nutrition, could be localized in the active areas of young bone and could play an important role in bone metabolism. ${ }^{5}$ Generally, $\mathrm{Si}$ is essential to the growth and development of 
biological tissue such as bone, teeth, and some invertebrate skeletons. ${ }^{6}$ In recent years, some researchers have reported that some Si-containing bioactive materials, such as bioactive glasses and Si-doped hydroxyapatite (HA), exhibited an excellent ability to induce bone-like apatite formation, both in vitro and in vivo. ${ }^{7-9}$ These studies suggested that $\mathrm{Si}$ ion played an important role in the nucleation and growth of apatite, and influenced the biological metabolism of osteoblastic cells essential in the mineralization process and in the bone-bonding mechanism. Furthermore, solution of high Si concentration showed the potential capacity to activate bone-related gene expression, stimulate osteoblast proliferation, and promote new bone formation. ${ }^{10}$

A study by Cortés et al ${ }^{11}$ showed that wollastonite exhibited excellent in vitro bioactivity, and the formation rate of apatite on its surface was faster than other biocompatible glasses and glass ceramics in simulated body fluid solution. In addition, wollastonite composites as plasma-sprayed coating on titanium alloy substrates and wollastonite-titanium dioxide or wollastonite-polymer composites showed good bioactivity and biocompatibility. ${ }^{12-14}$ Recently, emphasis has been placed upon the development of Si-based bioactive biomaterials in the field of orthopedics, owing to their unique functional properties. ${ }^{15}$ Lin et al $^{16,17}$ synthesized singlecrystalline wollastonite nanowires by different methods for biomedical application. There is no information available regarding wollastonite nanofiber (WNF)-doped CPC (wnfCPC) in the relevant literature. The purpose of the present study was to synthesize a self-setting bioactive cement by incorporation of WNFs into CPC. The composition, morphology/microstructure, setting time, compressive strength, hydrophilicity, and degradation of wnf-CPC were investigated, and the cell and tissue responses to wnf-CPC, both in vitro and in vivo, were also studied.

\section{Materials and methods Preparation and characterization of wnf-CPC}

WNFs were synthesized using a chemical precipitation method. Ca nitrate tetrahydrate $\left[\mathrm{Ca}\left(\mathrm{NO}_{3}\right)_{2} \cdot 4 \mathrm{H}_{2} \mathrm{O}\right]$ and sodium metasilicate nonahydrate $\left[\mathrm{Na}_{2} \mathrm{SiO}_{3} \cdot 9 \mathrm{H}_{2} \mathrm{O}\right]$ were used as the starting materials. The two reagents in 1:1 stoichiometric proportion were dissolved in deionized water in beakers and the concentration was adjusted to $0.5 \mathrm{~mol} / \mathrm{L}$. The $\mathrm{Ca}\left(\mathrm{NO}_{3}\right)_{2}$ solution was stirred while $\mathrm{Na}_{2} \mathrm{SiO}_{3}$ solution was added, and ammonia solution was used to keep the solution alkaline. After the precipitation was complete, wollastonite precipitate was obtained and this was fully washed with deionized water.
The wollastonite precipitate was dried at $120^{\circ} \mathrm{C}$ for 12 hours to obtain wollastonite powder samples. After that, the wollastonite powders were calcined at $700^{\circ} \mathrm{C}$ for 6 hours and were then ground for future use. The morphology of the wollastonite was examined using a field emission scanning electron microscope (FE-SEM) (S-4300SE; Hitachi Ltd, Tokyo, Japan).

The CPC powder consisted of TECP and DCPA in an equal molar ratio, and the preparation method was as previously described. ${ }^{18}$ Briefly, TECP was synthesized by a solid-to-solid reaction between $\mathrm{Ca}$ phosphate and $\mathrm{Ca}$ carbonate at a temperature of $1500^{\circ} \mathrm{C}$ for 8 hours. Dicalcium phosphate dihydrate was prepared from ammonium hydrogen phosphate and $\mathrm{Ca}$ nitrate in the acidic environment. DCPA was obtained by removing, over a period of 5 hours, the water of crystallization from dicalcium phosphate dihydrate kept at $120^{\circ} \mathrm{C}$. The TECP and DCPA powders were then mixed in a micromill (QM-2SP100, Nanjing, China) to form the CPC powder.

The wnf-CPC powder was prepared by adding WNF powder $(0,5,10,15$, and $20 \mathrm{wt} \%)$ into the CPC powder. The cement powder was mixed with water for 1 minute at the given powder-to-liquid $(\mathrm{P} / \mathrm{L})$ ratio and using a spatula to form a paste. The paste was then loaded into a cylindrical stainless steel mold and periodically packed by means of a stainless-steel rod to $2 \mathrm{~kg}$. The samples were transferred to a beaker, which was stored in an oven with a constant temperature of $37^{\circ} \mathrm{C}$ and at $100 \%$ relative humidity, and set for 48 hours till use. X-ray diffraction (XRD) (D/max 2550 VB/PC; Rigaku Corporation, Tokyo, Japan) and Fourier transform infrared spectroscopy (FT-IR) (Nicolet 5700; Thermo Electron Corporation, Madison, WI) were used to characterize the phase composition of WNFs, hardened wnfCPC with $10 \mathrm{wt} \%$ WNFs, and CPC. The surface morphology/ microstructure of the CPC and wnf-CPC were examined by FE-SEM. The cement samples were made in different sizes by using different molds.

\section{Setting time and compressive strength of wnf-CPC}

The wnf-CPC powder was mixed with deionized water according to the $\mathrm{P} / \mathrm{L}$ ratio designed to form pastes, and the pastes were then placed into glass tubes $(\Phi 6 \times 10 \mathrm{~mm})$. The top and bottom surfaces of the tubes were then covered tightly with two sheets of plastic film held by a C-clamp and were stored at $37^{\circ} \mathrm{C}$ in a $100 \%$ relative humidity box for setting. The samples were tested at various time intervals using a Vicat apparatus, which consists of a frame bearing a movable rod (weighing $300 \mathrm{~g}$ ) with a $\Phi 1 \mathrm{~mm}$ stainless steel 
needle at the end. The setting time was taken as the time at which the paste hardened to such an extent that a needle would not penetrate past $1 \mathrm{~mm}$ into the sample - this was according to the American Society for Testing and Materials C 187-98 standard test method for normal consistency of hydraulic cement, calling the Vicat method, to determine the setting time (ISO-Vicat, Hong Yu Inc, Cang Zhou, Hebei Province, China). Each test was repeated five times for each group and the average value was calculated. After hardening for 48 hours, the cement sample was uniformly polished on both sides. The compressive strength of the hardened sample of $\Phi 6 \times 10 \mathrm{~mm}$ was measured at a loading rate of $1 \mathrm{~mm}$ per minute, using a universal testing machine (Shimadzu Autograph AG-2000A; Shimadzu Co, Ltd, Tokyo, Japan). The measurement was performed three times for each group, and the results are expressed as mean plus or minus standard deviation.

\section{Hydrophilicity and porosity of wnf-CPC}

The surface hydrophilicity of wnf-CPC dense wnf-CPC specimens $(10 \times 10 \times 2 \mathrm{~mm}$ in size $)$ was determined by the contact angle of water droplets on the specimen surfaces produced under high pressure, using a contact angle measurement system (OCA-20; DataPhysics, Filderstadt, Germany). The water contact angle method was employed to determine the polar interactions across the material-water interface. Water droplets of $10 \mu \mathrm{L}$ were dropped onto four different points of each sample surface and water contact angles were measured after 10 seconds.

The porosity of wnf-CPC specimens $10 \times 10 \times 2 \mathrm{~mm}$ in size was evaluated using a mercury intrusion device (AutoPore IV 9500; Micromeritics Instrument Corporation, Norcross, GA). This device could measure pore size distribution in the range of $0.006-360 \mu \mathrm{m}$, but in this study any pores larger than $10 \mu \mathrm{m}$ were not considered micropores and so were not included in the porosity calculation.

\section{Degradation in tris hydrochloride solution}

The degradation of wnf-CPC was evaluated by weighing the remaining wnf-CPC samples after soaking and it was expressed as a percentage of the initial weight. The wnf-CPC samples $10 \times 10 \times 2 \mathrm{~mm}$ in size were soaked in $0.05 \mathrm{M}$ tris hydrochloride (tris- $\mathrm{HCl})$ solution $(\mathrm{pH} 7.40)$ at $37^{\circ} \mathrm{C}$ with a liquid-to-solid ratio of $0.4 \mathrm{~mL} / \mathrm{mg}$, and the medium was refreshed every week. For this evaluation, the samples were removed after incubation for specified time periods, rinsed in distilled water, and dried in a vacuum oven until constant weight was attained. All values presented are the average of five tests performed for each sample. The percentage of weight loss was calculated by the following equation (where $W_{0}$ is the starting dry weight and $W_{t}$ is the dry weight at time $t$ ):

$$
\text { Weight loss }(\%)=100 \times\left(W_{0}-W_{t}\right) / W_{0}
$$

Ionic concentrations of $\mathrm{Ca}$, phosphorus $(\mathrm{P})$, and $\mathrm{Si}$ in the tris- $\mathrm{HCl}$ solution were measured with an inductively coupled plasma atomic emission spectrometer (IRIS 1000; Thermo Elemental, Waltham, MA) at different time points. The surface morphologies of CPC and wnf-CPC with $10 \mathrm{wt} \%$ WNFs immersed in tris- $\mathrm{HCl}$ solution for 5 weeks were examined by FE-SEM.

\section{Cell attachment, proliferation, and morphology}

To investigate cell attachment and proliferation, dense CPC and wnf-CPC with $10 \mathrm{wt} \% \mathrm{WMF}$ samples $(10 \times 10 \times 2 \mathrm{~mm}$ in size) were sonicated in ethanol and sterilized by ethylene oxide. For cell adhesion experiments, MG-63 cells were seeded on the samples at a density of $5 \times 10^{3}$ cells per sample. Cells were allowed to adhere for 1 hour before each well was gently flooded with 1 milliliter of medium (L-Dulbecco's modified Eagle's medium containing $2 \%$ antibiotics). Cell attachment was determined using a methyl-thiazolyl-tetrazolium bromide (MTT) assay after incubation for 4 hours. In brief, sample cell constructs were placed in a culture medium containing MTT and incubated in a humidified atmosphere at $37^{\circ} \mathrm{C}$ for 4 hours. Cell growth was determined using the MTT assay (Cell Proliferation Kit I; Roche Diagnostics Corp, Indianapolis, IN). The optical density (OD) at $590 \mathrm{~nm}$ was measured with an ultraviolet-visible spectrophotometer (Cary 500; Varian Medical Systems, Inc, Palo Alto, CA). Six specimens were tested at each incubation period, and each test was performed five times per specimen. The results are reported as OD units.

Cell proliferation was evaluated after seeding cells at a density of $5 \times 10^{3}$ cells per sample, followed by incubation for 1,4 , and 7 days, with the medium replaced every second day. Adhesion and viable cells on substrates were assessed quantitatively using the MTT assay. The morphologies of the cells cultured after 3 days in contact with both wnf-CPC and CPC samples were observed via an inverted light microscope (IMT2, A10PL; Olympus, Tokyo, Japan) and photographed.

MG-63 cells were incubated with wnf-CPC with $10 \mathrm{wt} \%$ WNFs and CPC in a humidified atmosphere of 5\% carbon dioxide at $37^{\circ} \mathrm{C}$. The morphology of the cells on wnf-CPC at 
3 days was observed by FE-SEM. A sample cell construct was removed at this same time point and was washed twice with phosphate buffer solution (PBS), followed by fixation with 4\% formalin in PBS ( $\mathrm{pH} 7.4$ ) for 20 minutes. The fixed construct was washed twice with PBS, dehydrated in a series of ethanol concentrations $(50,60,70,80,90$, and $100 \% \mathrm{v} / \mathrm{v}$, for 3 minutes each), and air-dried overnight in a desiccator. At time points of 4 hours and 1, 4, and 7 days, the cement samples were taken out from culture fluids, and the $\mathrm{Ca}, \mathrm{Si}$, and $\mathrm{P}$ ion concentrations of the culture fluids were measured with an inductively coupled plasma atomic emission spectrometer. The $\mathrm{pH}$ values of the culture fluids were also monitored at the time points of 4 hours and 1, 4, and 7 days, using a $\mathrm{pH}$ spectrometer (CyberScan pH 510, Eutech, Singapore).

\section{Evaluation of biocompatibility and osteogenesis in vivo}

Twenty-four healthy New Zealand white rabbits aged 6 months and with an average weight of $2.8 \mathrm{~kg}$ were divided into two groups of twelve animals for each kind of implant. Under general anesthesia and sterile conditions, the left femur of each rabbit was exposed and one defect $(\Phi 6 \mathrm{~mm})$ was drilled in the distal part of the femur. The bone cavities were carefully washed to eliminate bone debris and were dried with gauze. Cylindrical wnf-CPC with $10 \mathrm{wt} \%$ WNFs or CPC samples with the size of $\Phi 6 \times 5 \mathrm{~mm}$ were implanted into the defects in the rabbit femora. Four animals from each group were sacrificed by an abdominal injection of an overdose of sodium pentobarbital at 3, 6, and 12 weeks after implantation. The bone specimens were harvested immediately after sacrifice. For histological evaluation, the samples together with surrounding tissues were excised, fixed in 10\% neutral buffered formalin, decalcified, and embedded in paraffin. Tissue blocks were sectioned at $5 \mu \mathrm{m}$ in thickness, stained with hematoxylin and eosin, and then observed by optical microscope (Olympus).

To quantitatively determine the amount of newly formed bone, the authors statistically analyzed the histological sections after different implantation periods $(3,6$, and 12 weeks). Four pieces of the histological sections of each rabbit were randomly chosen for hematoxylin and eosin staining. Each section was observed under optical microscope (magnification, $\times 40$ ), and at least ten images were randomly obtained in one section. Using the image analytical software Image-Pro ${ }^{\circledR}$ Plus (Media Cybernetics, Inc, Bethesda, MD), new bone volume was expressed as the percentage of newly formed bone area within the original drilled defect area.

\section{Statistical analysis}

Statistical analysis was performed with the use of a Student's $t$-test. All results are expressed as mean plus or minus standard deviation from the five times the experiment was performed for each sample. Differences were considered statistically significant at $P<0.05$.

\section{Results \\ Setting time, compressive strength, and hydrophilicity}

The effects of WNF amounts on the properties of wnf-CPC are shown in Table 1. The setting time was prolonged while compressive strength decreased with the increase of WNF amounts in wnf-CPC. The changes in setting time and compressive strength of wnf-CPC were not obvious when the WNF amounts were not more than $10 \mathrm{wt} \%$. However, water contact angles on the wnf-CPC specimens were significantly reduced with an increase in the amount of WNFs $(P<0.01)$ (Table 1), indicating that WNFs improved hydrophilicity.

The effects of the $\mathrm{P} / \mathrm{L}$ ratio on the properties of wnf-CPC are shown in Table 2. The setting time clearly increased while compressive strength decreased with a decrease in the $\mathrm{P} / \mathrm{L}$ ratio of wnf-CPC, indicating that the $\mathrm{P} / \mathrm{L}$ ratio had significant effects on setting time and compressive strength. Furthermore, the microporosity of hardened wnf-CPC clearly increased with a decrease in the $\mathrm{P} / \mathrm{L}$ ratio. However, a $\mathrm{P} / \mathrm{L}$ ratio of 2.5 revealed the highest compressive strength and the most suitable setting time.

\section{Characterization of wnf-CPC}

The SEM images in Figure 1 show that the synthesized WNFs were uniformly fiber-like, with powder agglomerating among the particles. This may have been due to the small particle size, with high surface energy resulting in their aggregation. The WNF aggregations were composed of fiber-like grains $50-90 \mathrm{~nm}$ in diameter and $100-250 \mathrm{~nm}$ in length. The XRD

Table I Effects of wollastonite nanofiber (WNF) amounts on properties of WNF-doped calcium phosphate cement (CPC) (powder-to-liquid ratio, 2.5)

\begin{tabular}{lcll}
\hline $\begin{array}{l}\text { WNF amount } \\
\text { (wt\%) }\end{array}$ & $\begin{array}{l}\text { Setting time } \\
\text { (minutes) }\end{array}$ & $\begin{array}{l}\text { Compressive } \\
\text { strength } \\
\text { (MPa) }\end{array}$ & $\begin{array}{l}\text { Contact } \\
\text { angle } \\
\text { (degrees) }\end{array}$ \\
\hline 0 (ie, undoped CPC) & $8.2 \pm 0.2$ & $45.0 \pm 2.6$ & $61.6 \pm 0.2$ \\
5 & $9.2 \pm 0.2$ & $43.7 \pm 1.6$ & $34.5 \pm 0.3$ \\
10 & $10.5 \pm 0.4$ & $42.3 \pm 2.1$ & $15.7 \pm 0.9$ \\
15 & $21.5 \pm 0.4$ & $37.4 \pm 1.8$ & 0 \\
20 & $44.8 \pm 1.3$ & $32.1 \pm 2.2$ & 0 \\
\hline
\end{tabular}

Note: Data presented as mean plus or minus standard deviation. 
Table 2 Effects of powder-to-liquid (P/L) ratio on properties of wollastonite nanofiber (WNF)-doped calcium phosphate cement with 10 wt\% WNFs

\begin{tabular}{lcl}
\hline P/L ratio $\left(\mathrm{g} \mathrm{mL}^{-1}\right)$ & $\begin{array}{l}\text { Setting time } \\
\text { (minutes) }\end{array}$ & $\begin{array}{l}\text { Compressive } \\
\text { strength }(\mathbf{M P a})\end{array}$ \\
\hline 3 & $8.3 \pm 0.2$ & $38.0 \pm 2.5$ \\
2.5 & $10.5 \pm 0.4$ & $42.3 \pm 2.1$ \\
2 & $15.8 \pm 0.5$ & $37.3 \pm 2.2$ \\
1.5 & $36.3 \pm 1.2$ & $29.6 \pm 4.6$ \\
1 & $56.0 \pm 2.2$ & $19.2 \pm 5.8$ \\
\hline
\end{tabular}

Note: Data presented as mean plus or minus standard deviation.

patterns of WNFs, CPC, and wnf-CPC with $10 \mathrm{wt} \% \mathrm{WNFs}$ are shown in Figure 2A. Peaks of $26^{\circ}, 32^{\circ}, 34^{\circ}, 40^{\circ}, 50^{\circ}$, $51^{\circ}, 52^{\circ}$, and $53^{\circ}$ show that HA existed in the wnf-CPC, and the characteristic peak of $29.3^{\circ}$ shows that WNFs also existed in the wnf-CPC: the results show that the wnf-CPC contained HA and WNFs.

Figure 2B shows FT-IR patterns of WNFs, CPC, and wnf$\mathrm{CPC}$ with $10 \mathrm{wt} \% \mathrm{WNFs}$. A structure of HA is indicated by 564,601 , and $1041 \mathrm{~cm}^{-1}$ of $\mathrm{PO}_{4}{ }^{3-}$ and $3570 \mathrm{~cm}^{-1}$ of $-\mathrm{OH}^{-}$, and the peaks of 1420 and $1560 \mathrm{~cm}^{-1}$ indicate the existence of WNFs. The obvious peak for $-\mathrm{OH}^{-}$of WNFs was caused by the water of crystallization. The results also show that the wnf-CPC contained HA and WNFs.

The SEM images in Figure 3 show the surfaces of wnfCPC and CPC after setting for 48 hours at $37^{\circ} \mathrm{C}$ in $100 \%$ relative humidity. The $\mathrm{CPC}$ exhibited different morphology to wnf-CPC. The CPC contained numerous particle-like crystals of HA, while the wnf-CPC formed a web-like structure. HA crystal particles appear to have been embedded with WNFs in the web-like structure of the wnf-CPC.

\section{Degradation in tris- $\mathrm{HCl}$ solution}

The degradation rate of $\mathrm{CPC}$ and wnf-CPC with different WNF amounts $(5,10,15$, and $20 \mathrm{wt} \%)$ over time was characterized by the weight loss ratio in tris- $\mathrm{HCl}$ solution.
The degradation rate of wnf-CPC clearly increased with the increase of WNF amounts, as shown in Figure 4. In contrast, CPC lost only $6.2 \%$ of its initial weight at the end of the experiment, which showed a significantly low weight loss ratio. The wnf-CPC with 10, 15, and $20 \mathrm{wt} \% \mathrm{WNFs}$ had a weight loss ratio of $17.4 \%, 22.9 \%$, and $28.2 \%$, respectively, of the initial weight. The weight loss ratio of the wnf-CPC was more than pure CPC plus WNFs (eg, 17.4\%>6.2\%+10\%), indicating not only that the WNFs dissolved but also that addition of WNFs promoted the degradation of CPC.

The changes of $\mathrm{Ca}, \mathrm{Si}$, and $\mathrm{P}$ ion concentrations of the tris$\mathrm{HCl}$ solution after soaking the wnf-CPC over time are shown in Figure 5. The concentrations of $\mathrm{Ca}$ and $\mathrm{Si}$ rose steeply while that of $\mathrm{P}$ increased more slowly, which indicated that wnf-CPC continuously released $\mathrm{Ca}$ and $\mathrm{Si}$ into the solution. The release speed of $\mathrm{Ca}$ and $\mathrm{Si}$ was initially high because of the quick dissolution of $\mathrm{Ca}$ silicate. The increase of $\mathrm{Ca}$ was mainly caused by dissolution of WNFs. HA is more stable than other $\mathrm{Ca}$ phosphates in its natural condition, so the concentration of $\mathrm{P}$ in the solution increased slowly.

The SEM images in Figure 6 show the surface morphology of wnf-CPC and CPC after immersion in tris- $\mathrm{HCl}$ solution for 5 weeks. Degradation of wnf-CPC seems to have occurred, while there is little evidence for the degradation of CPC. A lot of micropores appeared on the wnf-CPC because of degradation of the WNFs, as shown in Figure 6A, which could also be proved by the increase in porosity of the wnfCPC (Table 3).

\section{Cell attachment, proliferation, and morphology}

The MTT assay was used to assess the number of cells that adhered to the various biomaterials because OD absorbance values can be used as an indicator of the number of cells. Cell attachment was determined using the MTT assay of MG-63 cells cultured on CPC, wnf-CPC, and a tissue culture
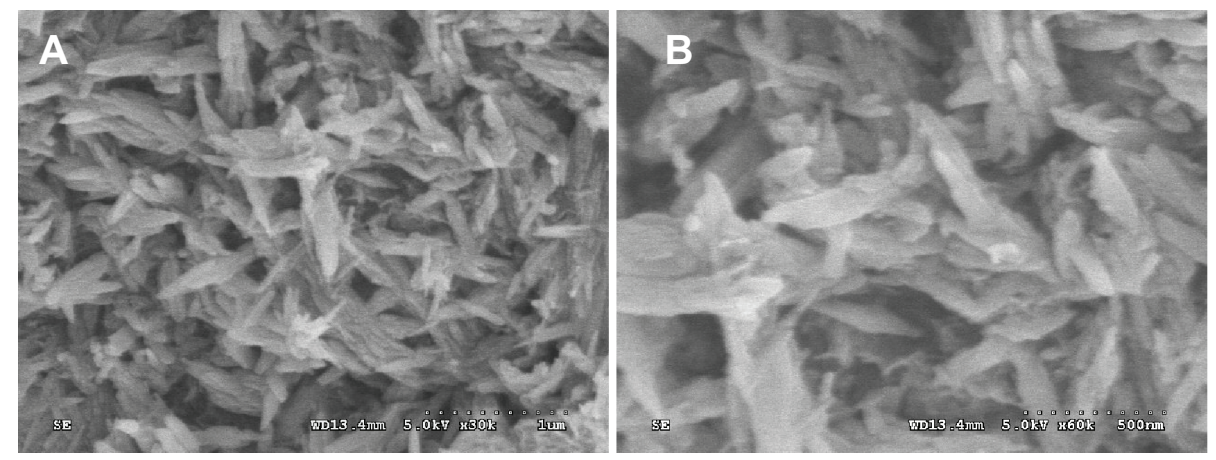

Figure I Scanning electron microscope images of wollastonite nanofibers with different magnifications: $($ A $) \times 30000$ and $($ B $) \times 60000$. 

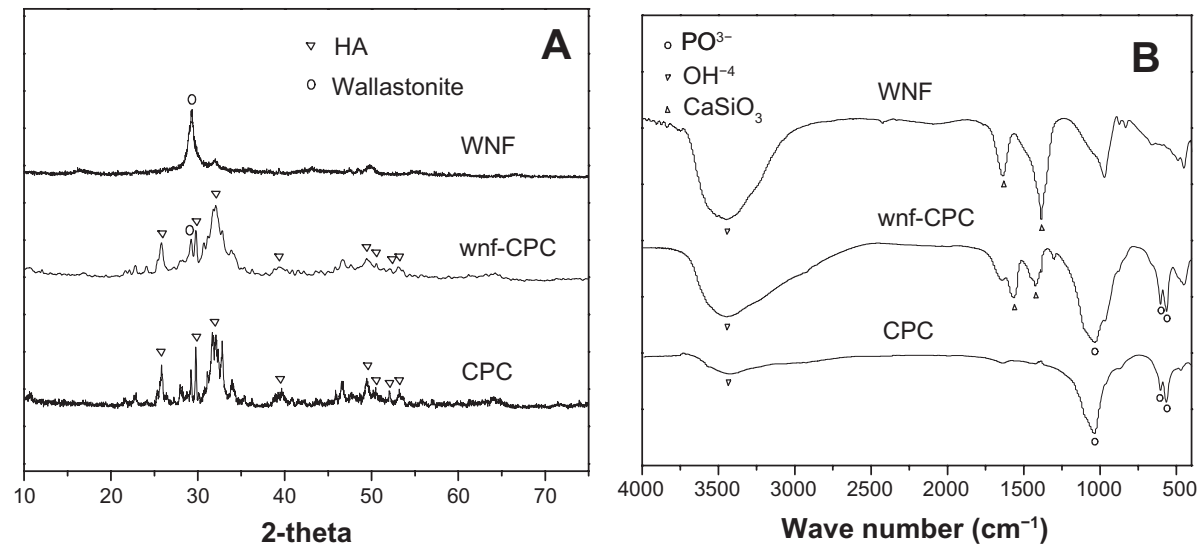

Figure 2 X-ray diffraction (A) and Fourier transform infrared spectroscopy (B) patterns of wollastonite nanofibers (WNFs), WNF-doped calcium phosphate cement (wnf-CPC) with 10 wt\% WNFs, and calcium phosphate cement (CPC).

Abbreviation: $\mathrm{HA}$, hydroxyapatite.

plate as a control. The cell attachment results are presented in Figure 7. After 4 hours, the OD value of wnf-CPC was significantly higher than for $\mathrm{CPC}$ or the control $(P<0.05)$. The result indicated that the cell attachment ratio on wnf-CPC was superior to that on CPC, suggesting wnf-CPC facilitated cell adhesion.

Proliferation of MG-63 cells cultured on CPC, wnf-CPC, and a tissue culture plate as control was assessed using the MTT assay because OD values can provide an indication of cell proliferation on various biomaterials. Figure 8 reveals that OD values for wnf-CPC were significantly higher than for CPC or the control after 4 and 7 days $(P<0.05)$ but that no significant difference appeared after 1 day. These results indicated that cell proliferation (after 4 and 7 days) for wnf$\mathrm{CPC}$ was superior to that for CPC $(P<0.05)$, suggesting that wnf-CPC facilitated cell growth and that it may promote cell proliferation.

Figure 9 shows inverted microscope images of cells cultured in contact with wnf-CPC and CPC for 3 days.
The morphology of the MG-63 cells was spindle-shaped and normal, and the cells were tightly combined with material surfaces. In addition, the amount of cells in contact with wnf-CPC was obviously greater than for CPC. The SEM images in Figure 10 show the morphological features of the cells cultured on CPC and wnf-CPC after 3 days. The cells had extended and spread well, exhibiting intimate contact with the surface of wnf-CPC and normal tissue. It was found that the morphology of cells attached on wnf-CPC was better than on CPC, and the amount of cells on wnf-CPC was also larger than on CPC.

In order to characterize the concentrations of ions released from wnf-CPC into the culture medium, the $\mathrm{Ca}, \mathrm{Si}$, and $\mathrm{P}$ ion concentrations of the culture medium were analyzed after cells had been cultured for different periods with wnf$\mathrm{CPC}$. The ionic concentrations and $\mathrm{pH}$ values of the culture medium at each time point are listed in Table 4 . The results show that $\mathrm{P}$ concentration increased gradually throughout the culture period, in contrast with the increasing $\mathrm{Ca}$ and $\mathrm{Si}$
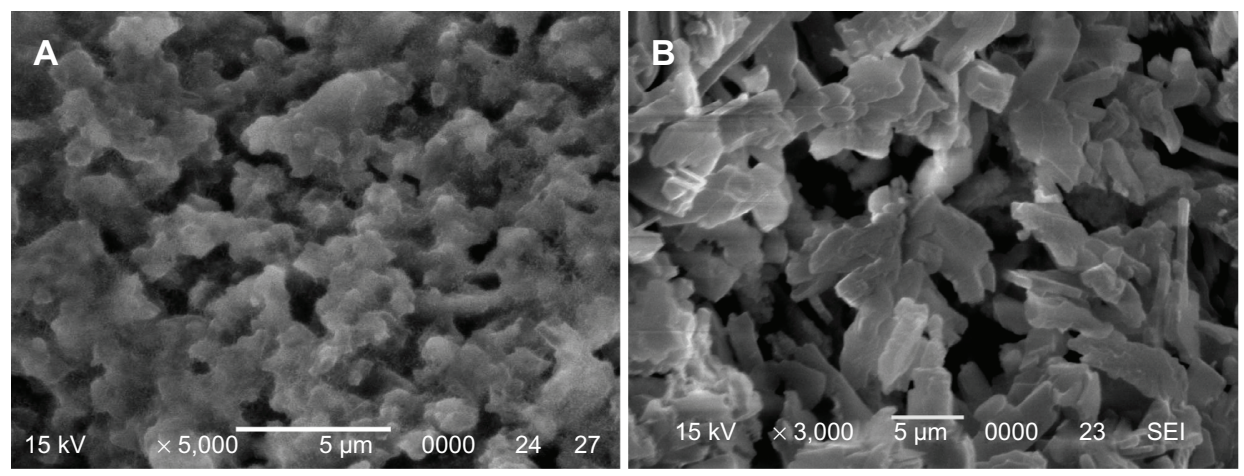

Figure 3 Scanning electron microscope images of surface morphology/microstructure of (A) wollastonite nanofiber-doped calcium phosphate cement with 10 wt\% wollastonite nanofibers and (B) calcium phosphate cement. 


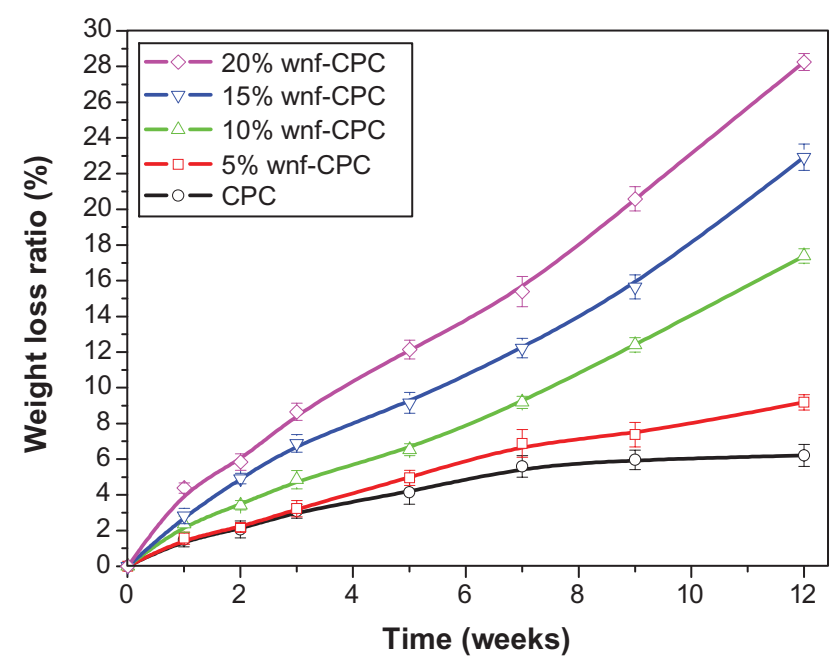

Figure 4 Weight loss ratio of wollastonite nanofiber (WNF)-doped calcium phosphate cement (wnf-CPC) and calcium phosphate cement (CPC) soaking in tris hydrochloride solution over time.

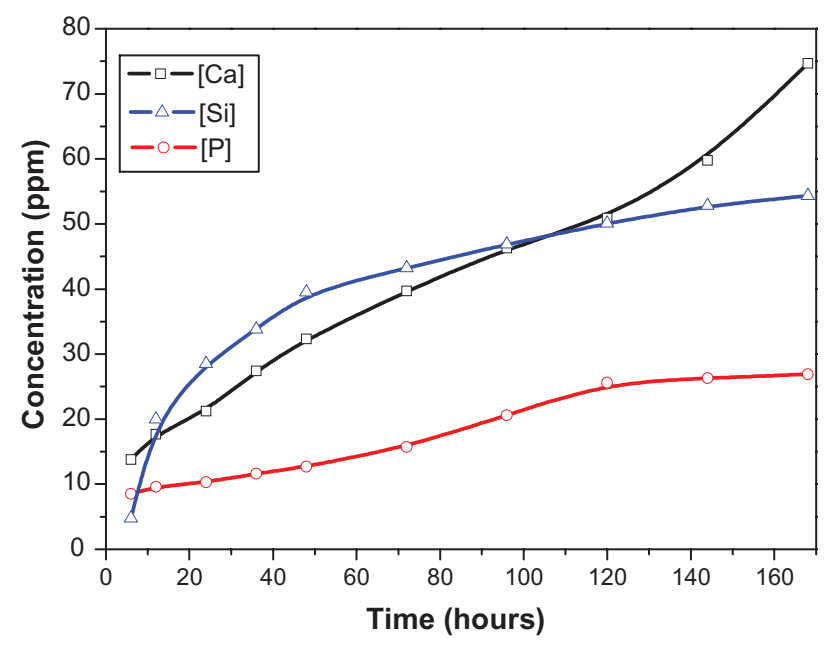

Figure 5 Changes in calcium $(\mathrm{Ca})$, silicon $(\mathrm{Si})$, and phosphorus $(\mathrm{P})$ ion concentrations in the tris hydrochloride solution for wollastonite nanofiber-doped calcium phosphate cement with 10 wt $\%$ wollastonite nanofibers over time. concentrations. Comparing between wnf-CPC and CPC, it was found that the concentration of both $\mathrm{Ca}$ and $\mathrm{P}$ was higher for wnf-CPC than for CPC. The $\mathrm{pH}$ values of the culture medium for wnf-CPC showed a slight increase in the first 4 days, followed by a gradual decrease toward 7.5 at the end of 7 days. The $\mathrm{pH}$ value for CPC slowly decreased, stabilizing at 7.0 at the end of 7 days.

\section{Implantation in vivo}

Macroscopic observation of wnf-CPC samples implanted into the bone defects of rabbit femora showed that the implants exhibited no foreign body reaction, no inflammation, and no necrosis in vivo. Histological evaluation results are shown in Figure 11. After 3 weeks' implantation, the wnf-CPC implant was encapsulated by bone tissue and the materials had started to degrade from the edge of the implant. After 6 weeks, the resorption of wnf-CPC continued, the new bone formation was found along the materials, and the new bone tissues formed were tightly combined with the implant. After 12 weeks, the newly formed bone that had grown into the pores of the materials replaced most of the wnf-CPC, and the interface between materials and host bone was tightly integrated. Histological evaluation of the CPC implanted into bone defects of rabbit femora was also performed. The results revealed that CPC only degraded marginally after 12 weeks and some new bone tissues formed along the materials. The results indicated that the in vivo degradation of wnf-CPC was superior to that of CPC.

The quantitative determination of newly formed bone was performed using statistical analysis of histological sections. The percentage of newly formed bone at the different implantation time periods is shown in Figure 12. The amount of newly formed bone in the defect area increased
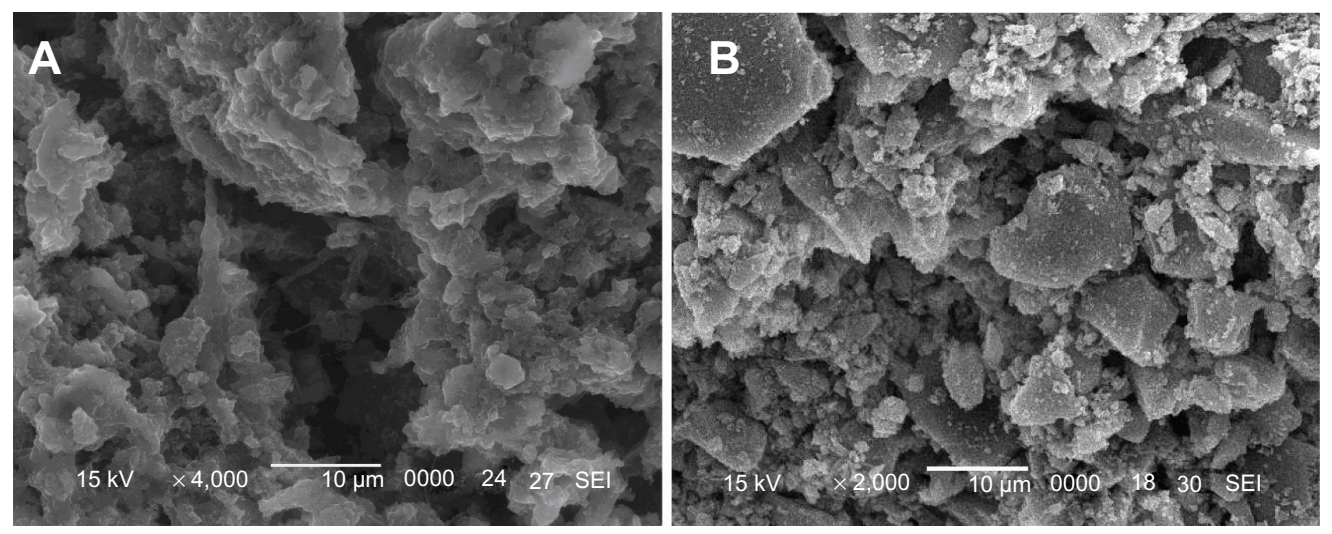

Figure 6 Scanning electron microscope images of surface morphology of (A) wollastonite nanofiber-doped calcium phosphate cement with 10 wt\% wollastonite nanofibers and (B) calcium phosphate cement immersed in tris hydrochloride solution for 5 weeks. 
Table 3 Effects of soaking time on porosity of calcium phosphate cement (CPC) and wollastonite nanofiber-doped CPC (wnf-CPC) with $10 \mathrm{wt} \%$ wollastonite nanofibers (powder-to-liquid ratio, 2.5)

\begin{tabular}{llr}
\hline Soaking time (weeks) & \multicolumn{1}{c}{ Porosity (\%) } \\
\cline { 2 - 3 } & wnf-CPC & \multicolumn{1}{c}{ CPC } \\
\hline 1 & $27.4 \pm 2.7$ & $6.7 \pm 1.2$ \\
4 & $34.3 \pm 3.2$ & $8.4 \pm 1.4$ \\
8 & $43.5 \pm 2.6$ & $9.3 \pm 1.0$ \\
12 & $55.7 \pm 2.4$ & $11.3 \pm 1.6$ \\
\hline
\end{tabular}

Note: Data presented as mean plus or minus standard deviation.

dramatically over time, together with the degradation of wnfCPC. After 12 weeks, the amount of newly formed bone was $65 \%$. However, after 12 weeks' implantation of CPC, the amount of newly formed bone was only $16 \%$. These results confirmed that wnf-CPC showed excellent biocompatibility, degradability, and osteogenesis, and that wnf-CPC exhibited greater bone-forming efficiency than CPC.

\section{Discussion}

$\mathrm{Si}$ is localized in active growth areas such as the osteoid of the young bone of mice and rats, and further evidence of the importance of $\mathrm{Si}$ on bone formation has been found in bioactive silicate containing glass ceramics. ${ }^{19,20}$ Therefore, in order to improve the biological properties of CPC, the present authors fabricated a bioactive cement of wnf-CPC by incorporation of WNFs into CPC. The results indicate that the addition of WNFs into CPC had no obvious effects on the setting time or compressive strength of wnf-CPC, provided the WNF amount was not more than $10 \mathrm{wt} \%$. The setting time of wnf-CPC increased only by about 2 minutes and compressive strength decreased by less than $4 \mathrm{MPa}$ with

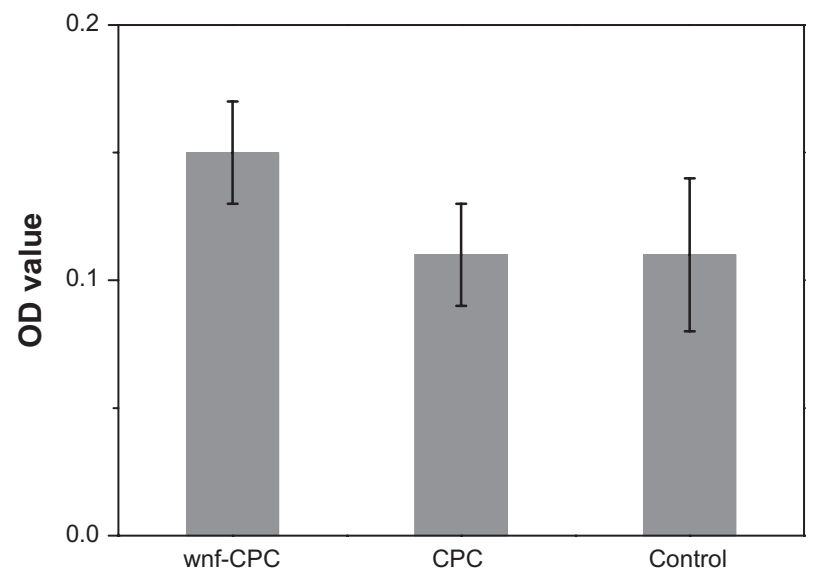

Figure 7 Methyl-thiazolyl-tetrazolium bromide assay of attachment ratio of MG63 cells on wollastonite nanofiber (WNF)-doped calcium phosphate cement (wnfCPC) with 10 wt\% WNFs, calcium phosphate cement (CPC), and a tissue culture plate as a control after being cultured for 4 hours.

Abbreviation: OD, optical density.

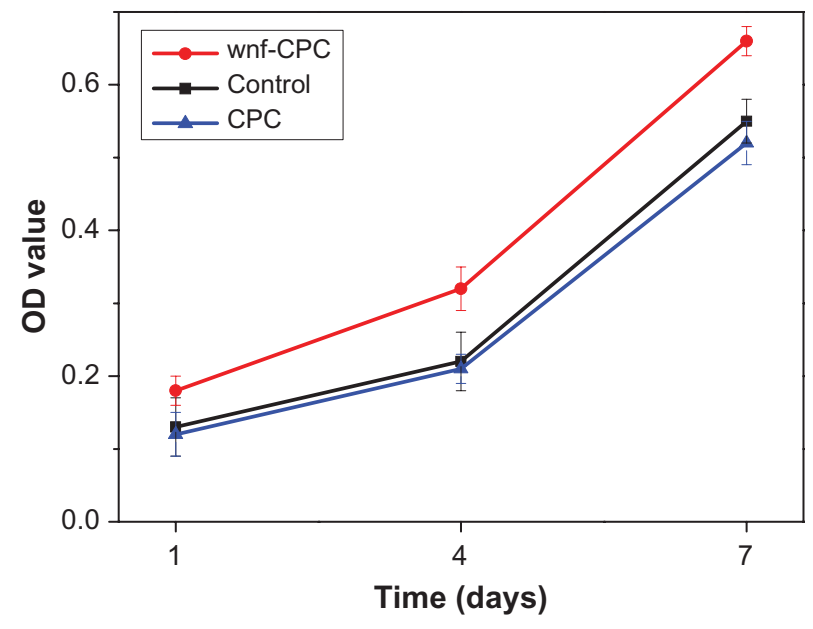

Figure 8 Methyl-thiazolyl-tetrazolium bromide assay of proliferation of MG-63 cells on wollastonite nanofiber (WNF)-doped calcium phosphate cement (wnf-CPC) with $10 \mathrm{wt} \% \mathrm{WNFs}$, calcium phosphate cement (CPC), and a tissue culture plate as a control at different times.

Abbreviation: OD, optical density.

the addition of a WNF amount not more than $10 \mathrm{wt} \%$. It was found that adding $10 \mathrm{wt} \% \mathrm{WNFs}$ into CPC was preferable because a combination of a setting time of 10.5 minutes and a compressive strength of $42.3 \mathrm{MPa}$ resulted in the value very close to the both peaks with the increased amount of WNF. However, the $\mathrm{P} / \mathrm{L}$ ratio significantly affected the properties of wnf-CPC. The setting time clearly increased with the decrease of the $\mathrm{P} / \mathrm{L}$ ratio, because of the slow hydrated reaction of CPC, and the porosity of wnf-CPC increased with a decrease of the $\mathrm{P} / \mathrm{L}$ ratio, so that the compressive strength of wnf-CPC decreased significantly. The results revealed that a $\mathrm{P} / \mathrm{L}$ ratio of 2.5 was preferable, because a setting time of 10.5 minutes and a compressive strength of $42.3 \mathrm{MPa}$ were ideal for filling bone defects.

Surface properties greatly affect the performance of the implanted materials. The hydrophilicity of biomaterials is an important factor for cell adhesion and growth. Improved surface hydrophilicity could promote interactions between the materials and cells in order to elicit controlled cellular adhesion and to maintain differentiated phenotypic expression. ${ }^{21,22}$ The hydrophilicity of wnf-CPC showed remarkable improvement compared with that of CPC, suggesting that the incorporation of hydrophilic WNFs was a viable method of improving the hydrophilicity of CPC. Alves et $\mathrm{al}^{23}$ reported that a material's hydrophilicity aided absorption of fibronectin, which is essential for osteoblast adhesion in vitro. Therefore, the greater hydrophilic surface of wnf-CPC may be better for cell attachment than CPC. From the results of XRD and FT-IR, the end product of wnf-CPC was mainly HA and wollastonite, indicating that addition 

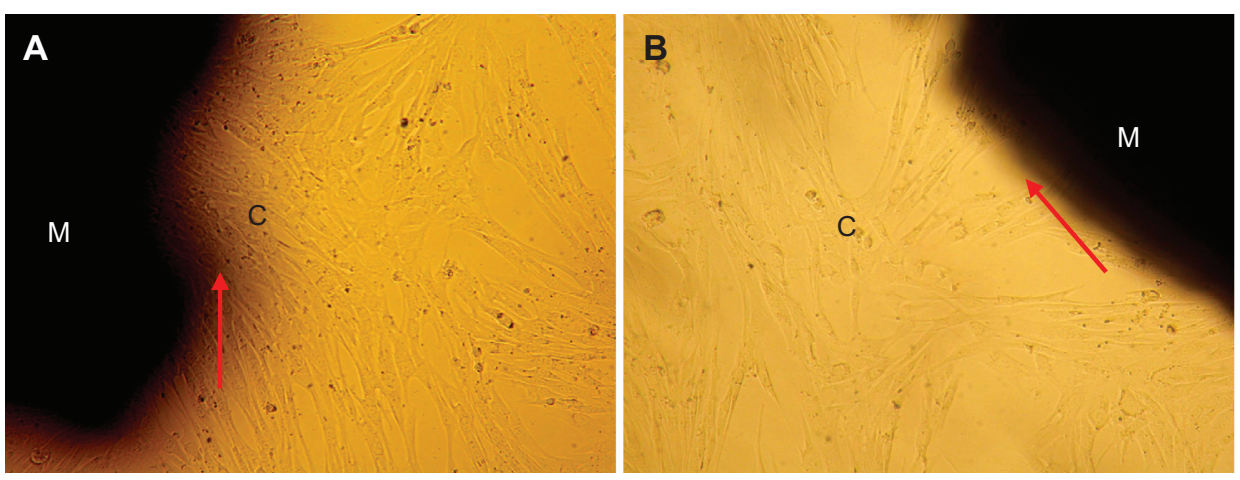

Figure 9 Morphology of cells cultured with samples for 3 days: (A) wollastonite nanofiber-doped calcium phosphate cement with 10 wt $\%$ wollastonite nanofibers and (B) calcium phosphate cement.

Notes: $M$ represents materials; $C$ represents cells; arrow indicates interface between materials and cells.

of WNFs did not affect phase composition and chemical structure of the hydrated products of CPC. The wollastonite seemed to be directly mixed with apatite and dispersed into the space among the apatite crystal particles; however, the peak of wollastonite was found to have weakened in the wnf$\mathrm{CPC}$ - it might be that some interaction between wollastonite and HA had occurred.

Proper degradation in a physiological environment is one of the most important characteristics of a biomaterial in its application for bone repair. ${ }^{24}$ The present study demonstrated that wnf-CPC exhibited noticeable weight loss in tris- $\mathrm{HCl}$ solution over time, indicating that wnf-CPC was degradable. In contrast, pure CPC did not show significant weight loss during incubation, losing only $6.2 \%$ of its initial weight. However, it was found that not only could WNFs dissolve but also the addition of WNFs into CPC could promote the dissolution of CPC. Furthermore, inductively coupled plasma atomic emission spectroscopy test results showed that $\mathrm{Ca}$ and $\mathrm{Si}$ ions were released first from wnf-CPC, and $\mathrm{P}$ ions were released slowly. It could be suggested that the degradation of WNFs was faster than HA (CPC) and, after the dissolution of WNFs, that wnf-CPC had more micropores, which may improve its surface area and thus promote the degradation of wnf-CPC when in contact with liquid.

Cellular responses to biomaterials can be influenced by the surface characteristics of biomaterials in vitro. Attachment is a part of the first phase of cell-material interactions, and the quality of this first phase will influence cell growth, morphology, proliferation, and differentiation upon contact with the implant. ${ }^{25}$ The results indicate that cells adhered better to wnf-CPC than CPC within the first 4 hours of culture. The superior ability of cells to attach to wnf-CPC compared with CPC is probably associated with different surface features of biomaterials. The addition of wollastonite may give wnf-CPC special surface properties - the wollastonite promoted cell attachment - and the more hydrophilic surface of wnf-CPC may also be more beneficial for cell adhesion.

There are some reports that ionic dissolution products containing $\mathrm{Ca}$ and $\mathrm{Si}$ from bioactive glasses could stimulate osteoblast proliferation and gene expression. ${ }^{26} \mathrm{Hench}$ et $\mathrm{al}^{27}$ found that a solution containing $\mathrm{Ca}, \mathrm{Si}$, and $\mathrm{P}$ ions could increase human osteoblast proliferation and differentially
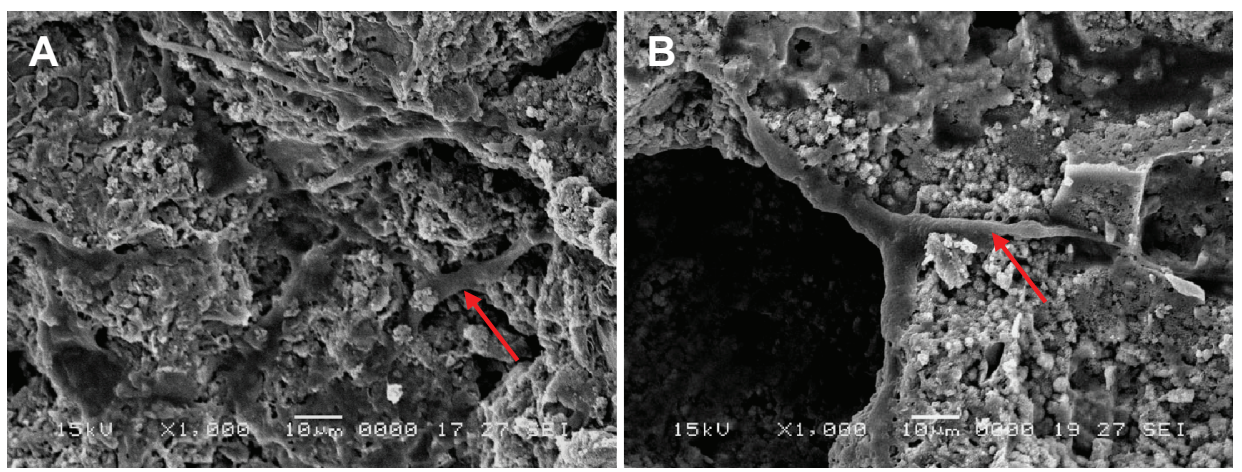

Figure 10 Scanning electron microscope images of MG-63 cells spread on (A) wollastonite nanofiber-doped calcium phosphate cement with I0 wt\% wollastonite nanofibers and on (B) calcium phosphate cement samples for 3 days.

Note: Arrow indicates cells. 
Table 4 Changes in calcium (Ca), silicon (Si), and phosphorus (P) concentrations and $\mathrm{pH}$ values in culture medium with time

\begin{tabular}{|c|c|c|c|c|c|c|c|c|}
\hline \multirow{3}{*}{$\begin{array}{l}\text { Time } \\
\text { (days) }\end{array}$} & \multicolumn{6}{|c|}{ Concentration (ppm) } & \multicolumn{2}{|c|}{ pH value } \\
\hline & \multicolumn{2}{|c|}{$\mathrm{Ca}$} & \multicolumn{2}{|l|}{ Si } & \multicolumn{2}{|l|}{$\mathbf{P}$} & \multirow{2}{*}{$\begin{array}{l}\text { wnf- } \\
\text { CPC }\end{array}$} & \multirow[t]{2}{*}{ CPC } \\
\hline & $\begin{array}{l}\text { wnf- } \\
\text { CPC }\end{array}$ & CPC & $\begin{array}{l}\text { wnf- } \\
\text { CPC }\end{array}$ & CPC & $\begin{array}{l}\text { wnf- } \\
\text { CPC }\end{array}$ & CPC & & \\
\hline 0 & 75.6 & 75.6 & NA & NA & 34.2 & 34.2 & 7.4 & 7.4 \\
\hline I & 96.4 & 88.3 & 28.6 & NA & 44.5 & 41.7 & 7.7 & 7.2 \\
\hline 4 & 120.8 & 103.1 & 46.1 & NA & 55.5 & 47.3 & 7.5 & 7.0 \\
\hline 7 & 149.2 & 111.9 & 55.2 & NA & 60.4 & 50.8 & 7.5 & 7.0 \\
\hline
\end{tabular}

Abbreviations: CPC, calcium phosphate cement; wnf-CPC, wollastonite nanofiberdoped calcium phosphate cement.

modulate gene expression, and another study has shown that sol-gel Bioglass ${ }^{\circledR}$ had a significant osteogenic effect through releasing a higher level of $\mathrm{Si}^{28}$ In the present study, the results show that the cell proliferation rate was higher on wnf-CPC than on $\mathrm{CPC}$, indicating that wnf-CPC significantly promoted cell proliferation. The wnf-CPC is a material that contains $\mathrm{Ca}$ and $\mathrm{Si}$, and the results show that $\mathrm{Ca}$ and $\mathrm{Si}$ ions could be released continuously from wnf-CPC into the cell culture medium. Only a small amount of $\mathrm{P}$ was released from $\mathrm{CPC}$, and the amount of $\mathrm{Ca}$ released from CPC was also lower than from wnf-CPC. Therefore, the continuous dissolution associated with wollastonite and $\mathrm{Ca}$ phosphate produces an environment rich in $\mathrm{Ca}$ and $\mathrm{Si}$, which may be responsible for stimulating cell proliferation. In conclusion, the wnf-CPC had positive effects on cell attachment and proliferation.

The biocompatibility of biomaterials is very closely related to the behaviors of the cells in contact with them, and particularly to cell spreading on the surface of the biomaterials. ${ }^{29}$ Observation using phase contrast microscopy indicated that the morphology of cells cocultured with wnf-CPC was normal and the cells tightly combined with materials; the amount of cells in contact with wnf-CPC was obviously greater than with $\mathrm{CPC}$, indicating that wnf-CPC had no negative effects on cell morphology and viability. The scanning electron microscopy results indicated that the cells extended and spread well, exhibiting intimate contact with wnf-CPC surfaces, and the amount of cells attaching to wnf-CPC was larger than for CPC. In addition, the process of cell spreading was influenced by the underlying substrates, and a past study has indicated that the appearance of bioactive biomaterials influenced the behavior and morphology of cells cultured on the surface of the materials. ${ }^{30}$ The results of the present study suggest that wnf-CPC had favorable surface for cell adhesion and growth and that it implied excellent biocompatibility.

The degradation of Ca phosphate-based biomaterials has been addressed in many studies, and chemical dissolution and cell-mediated resorption have been suggested for
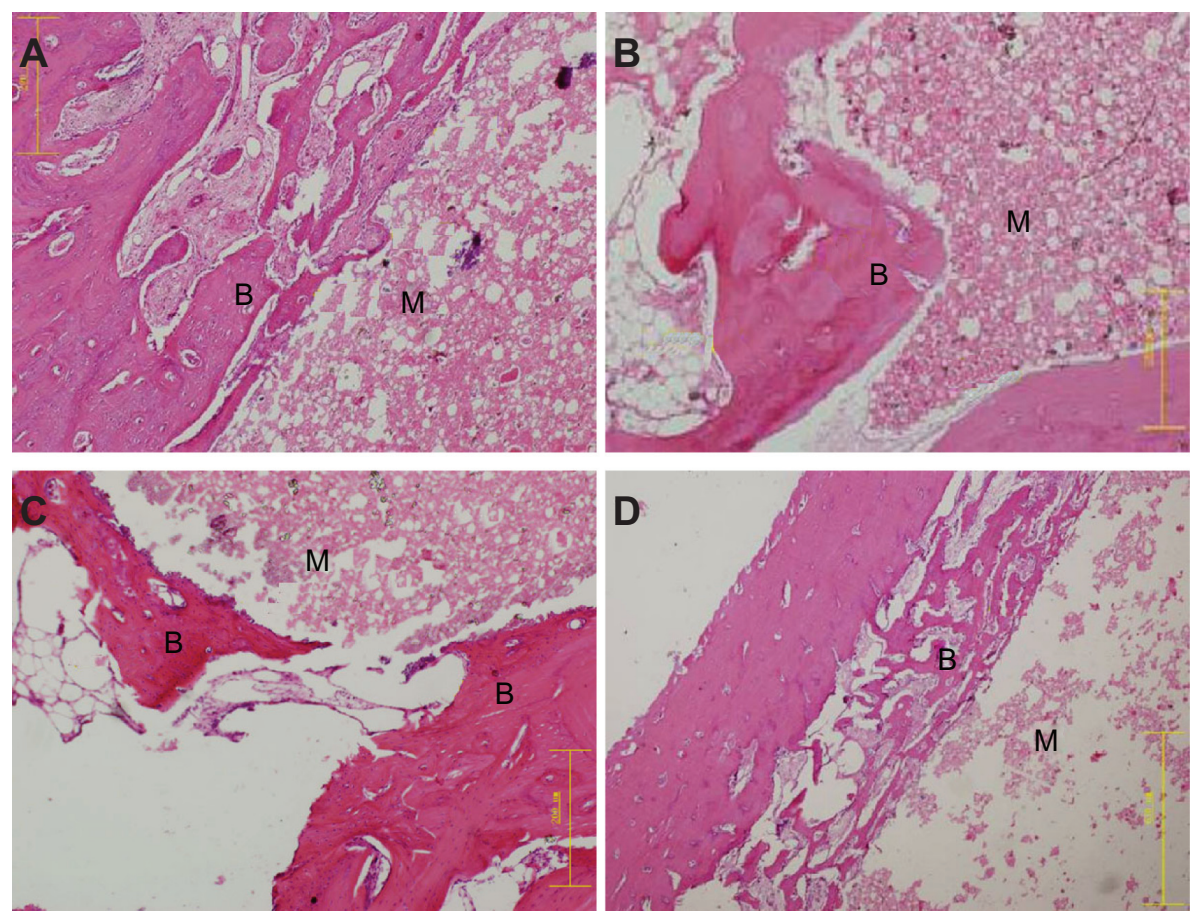

Figure II Hematoxylin and eosin-stained sections (magnification, $\times 20$ ) of wollastonite nanofiber-doped calcium phosphate cement with I0 wt\% wollastonite nanofiber samples implanted into bone defects of rabbit femora for (A) 3, (B) 6, and (C) 12 weeks, and of (D) calcium phosphate cement implanted for I2 weeks. Notes: B represents new bone tissues; $M$ represents implanted materials. 


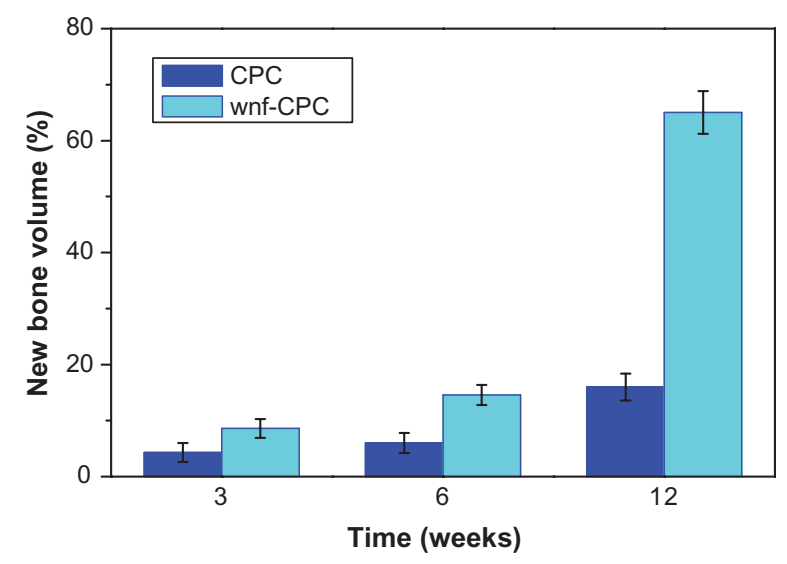

Figure 12 Histomorphometric analysis of bone defects repaired by wollastonite nanofiber-doped calcium phosphate cement (wnf-CPC) with $10 \mathrm{wt} \%$ wollastonite nanofibers and calcium phosphate cement (CPC) over time.

Notes: Data presented as mean plus or minus standard deviation; $\mathrm{n}=4$.

these biomaterials. ${ }^{31,32}$ In the present study, degradation of wnf-CPC was observed through the 12-week implantation in bone defects of rabbit femora. As the implantation time prolonged, new bone regenerated and gradually penetrated into the pores of the implants, accompanied by the resorption of the implanted materials. It is possible that chemical dissolution of the wnf-CPC occurred at the early stage of implantation. Dissolution at the initial stage of the experiment enlarged the microstructure of the implants, and osteoclastic cells also affected the degradation of wnf-CPC by creating a local acidic environment, which may facilitate cell-mediated resorption later. ${ }^{33}$ The area of wnf-CPC implants continued to decrease while the area of new bone tissue gradually increased, indicating that a cell-mediated resorption of wnf-CPC may occur. New bone deposited directly on the wnf-CPC surface while the resorption continued. Histological results confirmed that wnf-CPC implants exhibited high efficiency of bone regeneration. It is suggested that wnf-CPC exhibits not only good biocompatibility and degradability but also faster and more effective osteogenesis. These results indicate that such a good bone substitute could be developed as a potential implant for bone regeneration.

\section{Conclusion}

A bioactive cement, wnf-CPC, was fabricated and characterized by incorporation of WNFs into CPC. The results revealed that the addition of WNFs into CPC had no obvious effect on the setting time and compressive strength of the wnf-CPC, provided the WNF amount was not more than $10 \mathrm{wt} \%$. Furthermore, incorporation of WNFs into CPC could significantly improve the hydrophilicity and degradability. The wnf-CPC had special surface properties that could promote the attachment and proliferation of MG-63 cells. In addition, the dissolution associated with WNFs and $\mathrm{Ca}$ phosphate produces an environment rich in $\mathrm{Ca}$ and $\mathrm{Si}$, which may be responsible for stimulating cell growth and proliferation. Histological evaluation confirmed that wnf-CPC exhibited improved efficiency of bone regeneration. The results suggest that the improved biological properties of cell and tissue responses to wnf-CPC could contribute to special surface properties of the wnf-CPC, and to the release of $\mathrm{Ca}$ and $\mathrm{Si}$ ions into cell culture medium. In conclusion, wnf-CPC exhibited promising prospects in bone regeneration.

\section{Acknowledgments}

This study was supported by grants from the National Natural Science Foundation of China (Nos 31100680 and 30970720) National Basic Research Program of China (No 2010CB834301), External Cooperation Program of Chinese Academy of Sciences (No GJHZ09058), Nano Special Program of Science and Technology Development of Shanghai (No 1052nm06600), and Key Medical Program of Science and Technology Development of Shanghai (No 09411954900).

\section{Disclosure}

The authors report no conflicts of interest in this work.

\section{References}

1. Liu CS, Shao HF, Chen FY, Zheng HY. Effects of the granularity of raw materials on the hydration and hardening process of calcium phosphate cement. Biomaterials. 2003;24(23):4103-4113.

2. Brown WE, Chow LC, inventors; American Dental Association Health Foundation, assignee. Combinations of sparingly soluble calcium phosphates in slurries and pastes as mineralizers and cements. United States patent EP 4612053. September 16, 1986.

3. Tang M, Weir MD, Xu HH. Mannitol-containing macroporous calcium phosphate cement encapsulating human umbilical cord stem cells. J Tissue Eng Regen Med. 2012;6(3):214-224.

4. Guo H, Su JC, Wei J, Kong H, Liu C. Biocompatibility and osteogenicity of degradable $\mathrm{Ca}$-deficient hydroxyapatite scaffolds from calcium phosphate cement for bone tissue engineering. Acta Biomater. 2009; 5(1):268-278.

5. Liu XY, Ding CX, Wang ZY. Apatite formed on the surface of plasma-sprayed wollastonite coating immersed in simulated body fluid. Biomaterials. 2001;22(14):2007-2012.

6. Schwarz K, Milne DB. Growth-promoting effects of silicon in rats. Nature. 1972;239(5371):333-334.

7. Bosetti M, Cannas M. The effect of bioactive glasses on bone marrow stromal cells differentiation. Biomaterials. 2005;26(18):3873-3879.

8. Hing KA, Revell PA, Smith N, Buckland T. Effect of silicon level on rate, quality and progression of bone healing within silicate-substituted porous hydroxyapatite scaffolds. Biomaterials. 2006;27(29):5014-5026.

9. Porter AE. Nanoscale characterization of the interface between bone and hydroxyapatite implants and the effect of silicon on bone apposition. Micron. 2006;37(8):681-688.

10. Gupta G, Kirakodu S, El-Ghannam A. Dissolution kinetics of a Si-rich nanocomposite and its effect on osteoblast gene expression. J Biomed Mater Res A. 2007;80(2):486-496. 
11. Cortés DA, Medina A, Escobedo JC, Escobedo S, López MA. Effect of wollastonite ceramics and bioactive glass on the formation of a bonelike apatite layer on a cobalt base alloy. J Biomed Mater Res A. 2004; 70(2):341-346.

12. Cannillo V, Colmenares-Angulo J, Lusvarghi L, Pierli F, Sampath S. In vitro characterisation of plasma-sprayed apatite/wollastonite glassceramic biocoatings on titanium alloys. J Eur Ceram Soc. 2009;29(9): 1665-1677.

13. Liu XY, Ding CX. Plasma sprayed wollastonite $/ \mathrm{TiO}_{2}$ composite coatings on titanium alloys. Biomaterials. 2002;23(20):4065-4077.

14. Wei J, Chen FP, Shin JW, et al. Preparation and characterization of bioactive mesoporous wollastonite: polycaprolactone composite scaffold. Biomaterials. 2009;30(6):1080-1088.

15. Vallet-Regí M, Balas F, Colilla M, Manzano M. Bioceramics and pharmaceuticals: a remarkable synergy. Solid State Sci. 2007;9(9): $768-776$.

16. Lin KL, Chang J, Chen GF, Ruan ML, Ning CQ. A simple method to synthesize single-crystalline beta-wollastonite nanowires. J Cryst Growth. 2007;300(2):267-271.

17. Lin KL, Chang J, Lu JX. Synthesis of wollastonite nanowires via hydrothermal microemulsion methods. Mater Lett. 2006;60(24): 3007-3010.

18. Liu CS, Shao HF, Chen FY, Zheng H. Rheological properties of concentrated aqueous injectable calcium phosphate cement slurry. Biomaterials. 2006;27(29):5003-5013.

19. De Aza PN, Luklinska ZB, Santos C, Guitian F, De Aza S. Mechanism of bone-like formation on a bioactive implant in vivo. Biomaterials. 2003;24(8):1437-1445.

20. Oonishi H, Hench LL, Wilson J, et al. Quantitative comparison of bone growth behavior in granules of Bioglass ${ }^{\circledR}, \mathrm{A}-\mathrm{W}$ glass-ceramic, and hydroxyapatite. J Biomed Mater Res. 2000;51(1):37-46.

21. Liu XM, Lim JY, Donahue HJ, Dhurjati R, Mastro AM, Vogler EA. Influence of substratum surface chemistry/energy and topography on the human fetal osteoblastic cell line hFOB 1.19: phenotypic and genotypic responses observed in vitro. Biomaterials. 2007;28(31):4535-4550.

22. Verma S, Kumar N. Effect of biomimetic 3D environment of an injectable polymeric scaffold on MG-63 osteoblastic-cell response. Mater Sci Eng C Mater Biol Appl. 2010;30(8):1118-1128.
23. Alves CM, Yang Y, Marton D, et al. Plasma surface modification of poly(D,L-lactic acid) as a tool to enhance protein adsorption and the attachment of different cell types. J Biomed Mater Res B Appl Biomater. 2008;87(1):59-66.

24. Park SH, Gil ES, Kim HJ, Lee K, Kaplan DL. Relationships between degradability of silk scaffolds and osteogenesis. Biomaterials. 2010; 31(24):6162-6172.

25. Mandal BB, Das S, Choudhury K, Kundu SC. Implication of silk film RGD availability and surface roughness on cytoskeletal organization and proliferation of primary rat bone marrow cells. Tissue Eng Part A. 2010;16(7):2391-2403.

26. Varanasi VG, Saiz E, Loomer PM, et al. Enhanced osteocalcin expression by osteoblast-like cells (MC3T3-E1) exposed to bioactive coating glass $\left(\mathrm{SiO}_{2}-\mathrm{CaO}-\mathrm{P}_{2} \mathrm{O}_{5}-\mathrm{MgO}-\mathrm{K}_{2} \mathrm{O}-\mathrm{Na}_{2} \mathrm{O}\right.$ system) ions. Acta Biomater. 2009;5(9):3536-3547.

27. Hench LL, Xynos ID, Polak JM. Bioactive glasses for in situ tissue regeneration. J Biomater Sci Polym Ed. 2004;15(4):543-562.

28. Tu J, Wang YJ, Chen XF, Ou YJ, Qiu XZ. Bio-mineralization properties of Bioglass and effect of ionic products from Bioglass dissolution on osteoblast functions. J Inorg Mater. 2007;22(1):123-127.

29. Park JW, Kim YJ, Jang JH, Kwon TG, Bae YC, Suh JY. Effects of phosphoric acid treatment of titanium surfaces on surface properties, osteoblast response and removal of torque forces. Acta Biomater. 2010; 6(4):1661-1670.

30. Patlolla A, Collins G, Arinzeh TL. Solvent-dependent properties of electrospun fibrous composites for bone tissue regeneration. Acta Biomater. 2010;6(1):90-101.

31. Luo E, Hu J, Bao CY, et al. Sustained release of adiponectin improves osteogenesis around hydroxyapatite implants by suppressing osteoclast activity in ovariectomized rabbits. Acta Biomater. 2012;8(2): 734-743.

32. Detsch R, Mayr H, Ziegler G. Formation of osteoclast-like cells on HA and TCP ceramics. Acta Biomater. 2008;4(1):139-148.

33. Väänänen HK, Laitala-Leinonen T. Osteoclast lineage and function. Arch Biochem Biophys. 2008;473(2):132-138.
International Journal of Nanomedicine

\section{Publish your work in this journal}

The International Journal of Nanomedicine is an international, peerreviewed journal focusing on the application of nanotechnology in diagnostics, therapeutics, and drug delivery systems throughout the biomedical field. This journal is indexed on PubMed Central, MedLine, CAS, SciSearch $\AA$, Current Contents ${ }^{\circledR} /$ Clinical Medicine,

\section{Dovepress}

Journal Citation Reports/Science Edition, EMBase, Scopus and the Elsevier Bibliographic databases. The manuscript management system is completely online and includes a very quick and fair peer-review system, which is all easy to use. Visit http://www.dovepress.com/ testimonials.php to read real quotes from published authors. 